\title{
Los contratos con deberes de protección: a propósito de la vinculación entre el derecho constitucional y el derecho civil
}

\author{
Contracts with protection duties. A propos of Constitutional \\ and Civil Law connection
}

RÓMULO MORALES HERVIAS*

Resumen: El presente ensayo se refiere a los deberes de protección nacidos de contratos. El desarrollo doctrinal y jurisprudencial comparado de esta categoría es amplísimo. En el Perú, la doctrina nacional la ha estudiado a partir de casos concretos jurisprudenciales. El objetivo de este estudio es desarrollar la autonomía de estos deberes frente a las obligaciones principales y secundarias nacidas de contratos, con el fin de otorgarle una fundamentación no solo desde el derecho civil, sino también desde el derecho constitucional.

Palabras clave: contratos - obligaciones principales y secundarias - buena $\mathrm{fe}$ - constitucionalización del derecho civil - deberes de protección

Abstract: This essay examines protection duties arising under a contract. Its doctrinal and comparative case-law development is very broad. In Peru, national doctrine has studied it from case-law specific cases. The purpose of this study is to develop the analysis of autonomy of these duties towards main and secondary obligations arose under contracts in order to give legal bases not only from Civil Law but also from Constitutional Law perspective.

Key words: contracts - main and secondary obligations - good faith - civil law constitutionalization - protection duties

* Abogado por la Universidad de Lima. Magíster por la Universidad di Roma Tor Vergata. Diplomado en Derecho Romano, y en Derecho de los Consumidores y de la Responsabilidad Civil por la Universidad di Roma La Sapienza. Doctor por la Pontificia Universidad Católica del Perú. Profesor de Derecho Civil en la Pontificia Universidad Católica del Perú, en la Universidad Nacional Mayor de San Marcos y en la Universidad San Martín de Porres. Correo electrónico: romulo.morales@ pucp.pe 


\section{PROPÓSITO}

El propósito de este trabajo es analizar la existencia de contratos con deberes de protección, no solo porque tales deberes provienen de las reglas de la buena fe sino porque ellos tienen un fundamento constitucional en la dignidad de la persona humana, la cual debe ser respetada según el artículo 1 de la Constitución Política del Perú de 1993. Aquí, el derecho constitucional cumple «una función preservadora, de salvaguarda, con la cual protege el derecho (privado) existente» ${ }^{1}$.

El derecho privado, y en particular el derecho civil, ha desarrollado la categoría de los deberes de protección que se aplican a los contratos. En particular, las partes no solo están obligadas a ejecutar sus prestaciones sino que deben ejecutar prestaciones de protección entre ellas, teniendo en cuenta la naturaleza del contrato. Igualmente, los terceros son titulares activos de obligaciones de protección en atención a su exposición (fáctica o típica) a los riesgos de daños personales o patrimoniales provenientes de la ejecución de un determinado contrato. De esta manera, «a través de la individualización de los sujetos que pueden ser considerados "terceros", la doctrina y la jurisprudencia — sobre todo extranjera- ha intentado individualizar también el área en la cual el remedio contractual puede operar a favor del tercero. En tal sentido, se han expuesto en algunos sistemas, por un lado, la categoría del contrato con efectos protectores frente a terceros» ${ }^{2}$.

El derecho civil ha estudiado los contratos con efectos protectores basados en las reglas de la buena fe, y el derecho constitucional justifica dichas protecciones bajo la dignidad de la persona humana. El presente trabajo propone una lectura constitucional de los deberes de protección a favor de las partes contratantes y de los terceros.

Es importante señalar que las doctrinas ajenas a la alemana se resisten a admitir la concepción de los deberes de protección que «en el ambiente jurídico alemán, se origina y se desarrolla para atenuar los inconvenientes de la ausencia de previsión legislativa de una cláusula general de responsabilidad» ${ }^{3}$. El Código Civil peruano de 1984 sí tiene dicha cláusula, y por lo tanto, se podría deducir que es innecesario promover la aplicación de la concepción de las obligaciones de protección. En sentido diverso, sostendremos que no solo es necesario aplicar dicha concepción para proteger intereses en el ámbito de un contrato, sino que ella tiene una fundamentación constitucional.

1 HESSE, Konrad. Derecho constitucional y derecho privado. Ignacio Gutiérrez Gutiérrez (trad.). Madrid: Civitas, 1995, p. 349.

2 MOSCATI, Enrico. «Los remedios contractuales a favor de terceros». Ius et Veritas, XVI, 34 (2007), pp. 51-73, p. 53.

3 RoDotÀ, Stefano. Le fonti di integrazione del contratto. Milán: Giuffrè, 1969, p. 159. 
Una aclaración importante es que los deberes de protección son diferentes de las obligaciones de seguridad. Alguna doctrina colombiana los identifica ${ }^{4}$. Los deberes de protección «tienden a preservar la incolumidad de las partes contratantes ante posibles daños en su persona o bienes. La obligación de seguridad, en cambio, solo protege la integridad física de una de las partes, el acreedor».

Los deberes de protección «abarcan recíprocamente a ambas partes del vínculo obligatorio, a diferencia de la obligación, que solamente recae por sobre el acreedor». Los deberes de protección «comportan al menos en su mayor parte verdaderas obligaciones de prudencia y diligencia, a diferencia de las obligaciones de seguridad, que siempre, en su correcta acepción, son obligaciones de resultado» ${ }^{5}$.

Para una doctrina francesa, «un contrato no puede reforzar o atenuar la seguridad de alguien, en este caso la del contratante. Los daños corporales no constituyen supuestos de défaillances contractuelles [disfunción contractual o deficiencia contractual]. Ellos constituyen, muy por el contrario, supuestos de responsabilidad delictual, ya que el deber de velar por no causar daño corporal a otro recae sobre todos ${ }^{6}$. En Italia se ha dicho que la violación del deber de protección se regula por la responsabilidad extracontractual? .

Como explica una doctrina, los deberes de protección nacen en dos momentos: el descubrimiento de la culpa in contrahendo de Rudolf von Jhering, y el desarrollo de los deberes de protección [Schutzpflichten] de Heinrich Stoll. Así, la «culpa in contrahendo y la violación de los deberes de protección [basadas en el mismo presupuesto — violación de la esfera jurídica ajena - y pertenecientes al misma área de la responsabilidad contractual] en la ejecución del contrato son indicativas de lesiones iguales sobre el plano formal y solo diversas sobre el plano temporal». «Mientras Jhering buscaba responder positivamente a una exigencia de tutela para llenar una laguna de la responsabilidad aquiliana», por otro lado faltaba «una previsión por las violaciones contractuales positivas (positive Vertragsverletzungen, según la expresión de Hermann Staub que lo pone en evidencia), es decir, las hipótesis de comportamientos contrarios a la actuación del deber sin que el deudor esté en mora ni exista imposibilidad de la prestación» ${ }^{8}$.

4 Solarte Rodríguez, Arturo. "La buena fe contractual y los deberes secundarios de conducta». Universitas, 108 (2004), pp. 282-315, pp. 306-307. Bogotá: Facultad de Ciencias Jurídicas de la Pontificia Universidad Javeriana.

5 PrÉVôt, Juan Manuel. La obligación de seguridad. Segunda edición. Bogotá: Temis, 2012, pp. 287-288.

6 LE TOURNEAU, Philippe. «Breves comentarios críticos sobre la "responsabilidad contractual". El anteproyecto de reforma del derecho de la responsabilidad». José Luis GabRiEL RiverA (trad.). Revista Jurídica Thomson Reuters, I, 21 (2013), pp. 23-30, p. 29.

7 BARCELLONA, Mario. Trattato della responsabilità civile. Turín: Utet Giuridica, 2011, pp. 65-103.

8 CASTRONOVO, Carlo. «Obblighi di protezione». En Enciclopedia giuridica. Volume XXI., Roma: Istituto de la Enciclopedia Italiana, Istituto Poligrafico e Zecca dello Stato, 1990, pp. 1-12, p. 2.

LOS CONTRATOS

CON DEBERES DE

PROTECCIÓN:

A PROPÓSITO DE

LA VINCULACIÓN

ENTRE EL

DERECHO

CONSTITUCIONAL

Y EL DERECHO

CIVIL

CONTRACTS WITH

PROTECTION

DUTIES. A

PROPOS OF

CONSTITUTIONAL

AND CIVIL LAW

CONNECTION 
Sucesivamente se desarrolla la figura del contrato con efectos protectores para terceros [Vertrag mit Schtzwirkung für Dritte], que extiende la tutela contractual a terceros sobre la base del principio constitucional de la solidaridad ${ }^{9}$. Finalmente, las lesiones a la integridad física o patrimonial verificadas en el desarrollo de la actuación de la relación obligatoria constituyen - para otra doctrina alemana - violaciones de deberes de seguridad del tráfico [Verkehrssicherungspflichten], donde se aplica la responsabilidad extracontractual. Esta doctrina es objetada aduciendo que caben lesiones de situaciones subjetivas autónomas respecto del derecho de crédito en sentido estricto ${ }^{10}$.

Para una doctrina alemana, los deberes de protección nacen para corregir una debilidad del régimen alemán de responsabilidad extracontractual, la cual «radica en la estrecha responsabilidad por el hecho de terceros; es decir, por ejemplo, la responsabilidad que tiene el dueño de un negocio por la conducta dañosa de sus dependientes. Esta responsabilidad no es precisamente una responsabilidad estricta (objetiva), sino que requiere una culpa del dueño de la empresa, ya sea una culpa in eligendo o una culpa in vigilando» ( $\$ 831$ BGB: Numeral 1: Quien encarga a otro una actividad está obligado al resarcimiento del daño que el otro causa antijurídicamente a un tercero en la ejecución de la actividad. No se da el deber de resarcir si el dueño del negocio, en la elección de la persona encargada y, si debe suministrar dispositivos o medios materiales o está obligado a la dirección de la actuación, en el suministro o en la dirección, ha observado la diligencia exigible en el tráfico, o si el daño incluso con la observancia de dicha diligencia se hubiera producido igualmente).

Esta culpa se presume, pero el dueño puede desvirtuarla aduciendo prueba en contrario ${ }^{11}$. Y añade: «En muchos otros ordenamientos no es necesaria una justificación así de artificiosa; al contrario, bastaría con hacer uso de las reglas sobre responsabilidad extracontractual. Juristas alemanes también lamentan desde hace tiempo que los casos mencionados tienen naturaleza delictual y que una solución por medio del derecho de contratos es postiza» ${ }^{12}$.

Hace algún tiempo una doctrina italiana expresó lo siguiente: «La mayoría de los autores alemanes construyen [los deberes de protección] como elementos de una relación ex lege, diferentes de los efectos del contrato y como manto protector a la relación contractual. Correlativamente la categoría [de los deberes de protección] se extiende más allá del concepto de integración del contrato, hasta

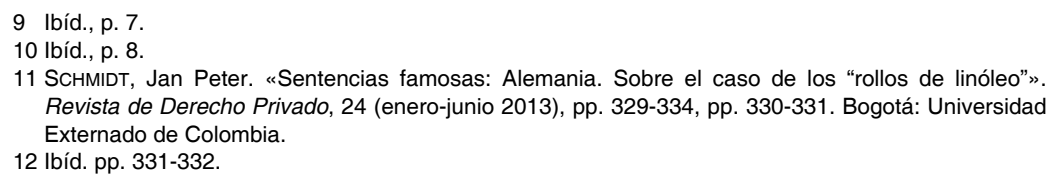


someterlo al régimen de responsabilidad contractual, incluyendo los daños ocasionados a la persona o a los bienes de una de las partes de comportamientos culposos de la otra, según los cuales la relación contractual solo es una simple ocasión» ${ }^{13}$.

\section{LA OBLIGACIÓN COMO RELACIÓN JURÍDICA COMPLEJA}

Un sector de la doctrina civil sostiene que el vínculo obligacional se caracteriza por la complejidad. Así, la obligación se entiende como un organismo, como una estructura y como un proceso. El alemán Heinrich Siber calificó a la obligación como un «organismo» [Organismus] que incluye un conjunto de créditos individuales, que corresponden a los deberes de prestaciones principales y accesorios, como también los derechos potestativos, que corresponden a las sujeciones ${ }^{14}$.

Otro autor alemán, Karl Larenz, configuró la obligación como una estructura o como un proceso. Desde este punto de vista, la obligación es una relación jurídica global donde se incluye un conjunto de deberes de prestación y otros deberes de conducta, también derechos potestativos y situaciones de sujeción. La obligación es un concepto-suma como un conjunto de consecuencias jurídicas (derechos subjetivos, poderes potestativos, deberes y sujeciones) relacionadas entre sí, en virtud de su conexión con el interés del acreedor, que debe ser satisfecho a través de esa relación. La obligación es una realidad jurídica compleja o una estructura de situaciones jurídicas, y también es una estructura temporal como un proceso evolutivo temporal ${ }^{15}$.

Esta concepción compleja de la obligación será útil para desentrañar el significado de los deberes de protección nacidos de los contratos. Esta concepción es más amplia que aquella que define la obligación como un vínculo personal entre dos sujetos, a través del cual uno de ellos puede exigir que el otro adopte determinado comportamiento en su beneficio. De ahí que se ha dicho adecuadamente que el carácter esencial de la obligación es ser relacional:

Es este carácter relacional el que, en el momento en que caracteriza la obligación, con o sin prestación, resulta ser el aspecto constante, el marco dentro del cual la prestación se inscribe solo como una posible variable. Así, la relación obligatoria deja de ser en su esencia

13 Mengoni, Luigi. Scritti. Obbligazioni e negozio. Vol. Il. A cura di Carlo Castronovo, Antonio Albanese y Andrea Nicolussi. Milán: Giuffrè, 2011, II, p. 287.

14 LeItÃo, Luís Manuel Teles de Menezes. Direito das obrigações. Volume I, Introdução, da constituição das obrigações. Quinta edición. Coimbra: Edições Almedina, 2006, pp. 85-86.

15 lbíd., pp. 86-87.

LOS CONTRATOS

CON DEBERES DE

PROTECCIÓN:

A PROPÓSITO DE

LA VINCULACIÓN

ENTRE EL

DERECHO

CONSTITUCIONAL

Y EL DERECHO

CIVIL

CONTRACTS WITH

PROTECTION

DUTIES. A

PROPOS OF

CONSTITUTIONAL

AND CIVIL LAW

CONNECTION 
deber de prestación y pasa a ser esa relación constante (konstante Rahmenbeziehung), teorizada por Herholz y acogida por Mengoni ${ }^{16}$.

La relación es una estructura orgánica, Organismus según la locución de la doctrina alemana que la teoriza -incluso parece mejor Gefüge, estructura-, si bien, a la inversa, la idea de relación marco que nace ex lege como consecuencia de la instauración de la confianza inicial entre las partes - y en la que, sin embargo, es la voluntad de estas la que inserta el deber de prestación- expresa mejor el doble aspecto de la estructura que en estos términos se origina ${ }^{17}$. En Alemania surge la teorización de la obligación como Organismus (Siber, Heinrich Stoll), como relación obligatoria en sentido amplio (Oertmann) o como relación marco $\left(\right.$ Herholz) ${ }^{18}$.

Así,

[...] la obligación es reconstruida como una estructura compleja, según la cual el núcleo principal está constituido por la obligación [obbligo] de prestación y está integrado por una serie de obligaciones [obblighi] accesorias coordinadas en un nexo funcional unitario. El aspecto más interesante de esta evolución está representado por la teoría de los «deberes [obblighi] de protección», que ha extendido la tutela de la relación obligatoria, y por ello el régimen de la responsabilidad contractual, al interés de ambas partes para preservar la propia persona y los propios bienes del riesgo específico de daño creado por la particular relación que se produce entre los dos sujetos ${ }^{19}$.

Dentro de este marco teórico, una relación obligatoria es compleja porque contiene deberes de prestaciones principales, deberes de prestaciones secundarias y deberes accesorios. La prestación principal es la acción humana, considerada como núcleo de la obligación ${ }^{20}$. La prestación secundaria depende de la prestación principal ${ }^{21}$. Y los deberes accesorios cautelan el vínculo obligacional; protegen a las partes, en sus personas o en su patrimonio, y protegen a los terceros, que con la obligación, tengan un especial contacto ${ }^{22}$. Estos deberes accesorios son denominados deberes de protección o deberes funcionales:

16 CASTRONOVO, Carlo. «La relazione come categoría essenziale dell'obbligazione y della responsabilità contrattuale». En Europa e diritto privato, 1. Milán: Giuffrè, 2011, pp. 55-76, pp. 66-67, y «La relación como categoría esencial de la obligación y de la responsabilidad contractual». César E. Moreno More (trad.) y Javier Rodríguez Olmos (rev.). Revista de Derecho Privado, 23 (julio-diciembre 2012), pp. 47-64, p. 57.

17 CASTRONOVO, Carlo. «La relazione come categoría essenziale...». Ob. cit., p. 70, y «La relación como categoría esencial...». Ob. cit., pp. 59-60.

18 CAstronovo, Carlo. «La relazione come categoría essenziale ...». Ob. cit., p. 68, y «La relación como categoría esencial...». Ob. cit., p. 58.

19 MENGONI, Luigi. Ob. cit., II, pp. 284-285.

20 Menezes CordeIRo, António. Tratado de Direito Civil Português. Volume II, Direito das Obrigações. Tomo I. Coimbra: Almedina, 2009, p. 455.

21 Menezes Cordeiro, António. Ob. cit., p. 462.

22 Menezes Cordeiro, António. Ob. cit., p. 465. 
Hago referencia a deberes funcionales y ya no de accesorios, precisamente porque dicha función accesoria puede ser predicada cuando exista un deber de prestación, que por el contrario, como estamos diciendo, no surge necesariamente o, cuando habiendo existido y habiéndose luego extinguido, no implica a su vez la extinción automática de los deberes llamados accesorios. Desde esta perspectiva, el elemento que hace permanente (konstante) la relación no está constituido por el deber de prestación, el cual precisamente por definición tiene una duración inferior a la de la relación en su conjunto, sino por esta última, que viene a denominarse relación jurídica fundamental. De esto se deriva que la esencia de la relación obligatoria — esencia entendida como lo que debe estar presente y no puede faltar- no está constituida por el deber de prestación, que precisamente puede faltar, sino por los hasta ahora denominados deberes accesorios que, sin embargo, por lo que hasta el momento hemos afirmado, es mejor denominar funcionales al correcto desarrollo de lo que - habiéndose originado en un contacto social cualificado- se convierte en una relación jurídica gracias a aquellos, relación que incrementa su contenido si a esto se suma el deber de prestación ${ }^{23}$.

Según un importante sector de la doctrina del derecho civil, los deberes de protección nacen no solo de los contratos sino también de los contactos sociales como el caso de las negociaciones donde se instaura entre las partes una relación social de la cual surgen recíprocos deberes dirigidos a proteger la esfera de intereses que aquella relación pone en peligro $^{24}$ :

En efecto, mientras el deber [obbligo] de prestación nace como consecuencia eventual de una fuente específica, en particular el contrato, los deberes [obbligi] y las situaciones de marco tienen fundamento en la ley sobre el presupuesto de una relación que se formó entre las partes. La diferencia entre estos dos aspectos de la relación está no solo en el contenido sino en el orden de prioridad, según el cual se refleja en las fuentes respectivas. Mientras la relación marco nace directamente de la ley, de reflejo de la calificación del contacto social según el criterio de la buena fe, la prestación nace necesariamente en el marco así formado pero no por efecto automático, sino por la elección específica que se sustancia en un contenido siempre diverso por la función de una precisa voluntad de las partes o de un fin [scopo] determinado. Pero siempre la relación marco es la relevancia jurídica de la relación formada sobre el plano del hecho, el deber [obbligo]

LOS CONTRATOS

CON DEBERES DE

PROTECCIÓN:

A PROPÓSITO DE

LA VINCULACIÓN

ENTRE EL

DERECHO

CONSTITUCIONAL

Y EL DERECHO

CIVIL

CONTRACTS WITH

PROTECTION

DUTIES. A

PROPOS OF

CONSTITUTIONAL

AND CIVIL LAW

CONNECTION 
de prestación es el efecto querido (por las partes o por la ley) específico que se coloca en tal relación ${ }^{25}$.

También hay deberes accesorios o deberes de protección que derivan de la ley, y en concreto del principio de la buena $\mathrm{fe}^{26}$.

En doctrina nacional se describió el desarrollo de los «deberes de protección» [Schutzpflichten] en Alemania e Italia ${ }^{27}$. Otra doctrina nacional ha argumentado que el deber de diligencia es un deber accesorio o deber de protección que nace de la ley:

Lo que el artículo 1314 realiza, en principio, es el enunciado general de la prueba del cumplimiento de las obligaciones con la actuación diligente del deudor (es decir que la mal llamada prueba de la «ausencia de culpa» es una prueba de cumplimiento de la obligación), cuando la conducta de protección asumida por el deudor en la situación jurídica subjetiva de deuda coadyuva a la consecución de la utilidad comprometida en el deber de prestación.

Pero, además, pocos han reparado en que, al referirse el artículo 1314 al deber accesorio de diligencia, brinda fundamento legal al acogimiento contractual integral de los deberes de protección, los cuales, a saber, pueden ser de dos clases:

a) Los que coadyuvan a la realización del deber central (a la realización del deber primario de prestación), contribuyendo en mayor o menor medida a precisar la forma particular de ejecución de la prestación debida en función del tipo de utilidad comprometida en el deber de prestación.

Aquí, los deberes de protección están destinados, pese a todo, a tutelar el interés de prestación (Ej.: en el transporte, trasladar a los pasajeros a destino, sanos y salvos; en las prestaciones médicoquirúrgicas, vigilar el desenvolvimiento de la propia conducta de manera tal que se le procure al paciente la utilidad inmaterial de mejorar su posición de salvamento, etcétera).

En esta hipótesis, al vincularse necesariamente el deber de protección de la obligación con la utilidad comprometida en el deber central, la ejecución de la diligencia debida no puede significar otra cosa que la no presentación de vicisitud alguna en el cumplimiento del deber central; es decir, el cumplimiento de la obligación.

25 CAStronovo, Carlo. «La relazione come categoría essenziale ...». Ob. cit., pp. 68-69.

26 BenATTI, Francesco. Ob. cit., p. 1346.

27 LEÓN, Leysser. «La importancia del derecho comparado en la reforma del Código Civil y en la formación de una verdadera escuela de civilistas peruanos. A propósito de la modernización del derecho de obligaciones en Alemania (Schuldrechtsmodernisierung)». Ius et Veritas, XIII, 26 (2003), pp. 12-46, pp. 36-38. 
b) Los que tienen la específica función de tutelar a la persona y los bienes de la otra parte de la relación.

Es decir, que también el artículo 1314 (concordado con el artículo 1362 del mismo) recoge la protección contractual del respeto a la esfera jurídica del acreedor (deberes de seguridad), recogiéndose la exigencia de tutela de la persona y de las cosas de cada uno de los sujetos de la relación obligatoria que no tienen por qué «sufrir daños a causa o con ocasión del desarrollo de la relación».

Empero, a diferencia de los deberes de protección que coadyuvan a la realización del deber central, aquí el deber accesorio de diligencia, encarnado en un deber de seguridad, tutela, no ya el interés de prestación, sino exclusivamente el interés de protección, cuya lesión puede dar también lugar, sin duda, a una responsabilidad contractual.

En esta hipótesis, entonces, el cumplimiento del deber de diligencia no conlleva el cumplimiento del deber central y, por lo tanto, no representa una prueba del cumplimiento de la obligación, sino, tan solo, la satisfacción de un interés de protección autónomamente considerado en sede contractual ${ }^{28}$.

No obstante lo señalado, un sector de la doctrina italiana ha advertido que la diligencia «no puede ser considerada fuente de obligaciones, autónomas o accesorias» sino que es «un criterio de responsabilidad en relación de una prestación ya determinada en su conjunto» ${ }^{29}$. «La diligencia se presenta como un criterio de valoración sin que forme parte del contenido de una obligación autónoma» ${ }^{30}$. Así, la diligencia es un instrumento de control de la actividad del deudor: «ella se refiere solo al cómo de la prestación» ${ }^{31}$. Otra doctrina italiana ha expresado que el desarrollo de la actividad ejecutiva «está dominado por la regla de la diligencia» ${ }^{32}$.

En el presente estudio nos vamos a concentrar en los deberes de protección nacidos de los contratos. Por ejemplo, el contrato de arrendamiento genera una relación obligatoria compleja donde coexisten obligaciones principales del arrendador de entregar el bien (artículo 1678 del Código Civil) y de mantener al arrendatario en el uso del bien durante el plazo del contrato (numeral 1 del artículo 1680 del Código Civil), y deberes de protección del arrendador de conservar

28 FERNÁNDEZ CRUZ, Gastón. «El deber accesorio de diligencia y la responsabilidad derivada del incumplimiento en las relaciones obligatorias». Advocatus, 13 (2005), pp. 143-161, p. 159. Lima: revista de los alumnos de la Facultad de Derecho de la Universidad de Lima.

29 RODOTÀ, Stefano. Le fonti di integrazione del contratto. Ob. cit., p. 160.

30 RodotÀ, Stefano. «Diligenza» (Diritto civile). En Enciclopedia del diritto. Tomo XII. Varese: Giuffrè,1964, pp. 539-546, p. 544.

31 Rodotà, Stefano. Le fonti di integrazione del contratto. Ob. cit., p. 153. De acuerdo: RavazzonI, Alberto. «Diligenza». En Enciclopedia giuridica. Volume XI. Roma: Istituto de la Enciclopedia Italiana, Istituto Poligrafico e Zecca dello Stato, 1989, pp. 1-6, p. 2.

32 RomAno, Salvatore. «Buona fede» (Diritto privato). En Enciclopedia del diritto. Tomo V. Varese: Giuffrè Editore, pp. 677-700, p. 689.

LOS CONTRATOS

CON DEBERES DE

PROTECCIÓN:

A PROPÓSITO DE

LA VINCULACIÓN

ENTRE EL

DERECHO

CONSTITUCIONAL

Y EL DERECHO

CIVIL

CONTRACTS WITH

PROTECTION

DUTIES. A

PROPOS OF

CONSTITUTIONAL

AND CIVIL LAW

CONNECTION 
el bien en buen estado para el fin del arrendamiento (numeral 1 del artículo 1680 del Código Civil) y de realizar las reparaciones necesarias (numeral 2 del artículo 1680 del Código Civil). Además, hay otras obligaciones principales del arrendatario de recibir el bien (numeral 1 del artículo 1681 del Código Civil), de cuidar el bien diligentemente (numeral 1 del artículo 1681 del Código Civil), de usar el bien para el fin según el contrato o las circunstancias (numeral 1 del artículo 1681 del Código Civil), de pagar oportunamente la renta y los servicios públicos suministrados (numerales 2 y 3 del artículo 1681 del Código Civil), y de restitución del bien en el plazo debido y en el estado del normal deterioro (numeral 10 del artículo 1681 del Código Civil).

Asimismo, hay la obligación secundaria de permitir al arrendador la inspección por causa justificada [carga del arrendador de avisar siete días antes] (numeral 5 del artículo 1681 del Código Civil), y obligación secundaria negativa de uso imprudente del bien o con fin ilícito [motivo del arrendatario contrario al orden público o a las buenas costumbres] (numeral 7 del artículo 1681 del Código Civil). Finalmente, están reguladas la obligación de protección de dar aviso inmediato al arrendador de cualquier posible peligro de perjuicio al bien (numeral 4 del artículo 1681 del Código Civil), la obligación de protección de hacer las reparaciones según la ley o el contrato (numeral 6 del artículo 1681 del Código Civil), y la obligación de protección negativa de no introducir cambios ni modificaciones en el bien (numeral 8 del artículo 1681 del Código Civil).

En consecuencia, esta concepción de la obligación como relación jurídica compleja se extiende a la categoría de la obligación sin prestación. Una concepción de la obligación relacionada con la prestación era inconcebible hace un tiempo. Pero como se ha dicho correctamente, existen prestaciones sin obligación, como en la gestión de negocios y en el caso de un médico cuando por iniciativa propia opere a un enfermo que no se encuentra en las condiciones de solicitar su intervención, por ejemplo, si el primero se encontraba casualmente en las inmediaciones de un accidente ${ }^{33}$.

Asimismo, cabe hablar de la obligación sin prestación en los casos de la obligación sin prestación del médico frente al paciente, a diferencia de la obligación con prestación del médico frente a la estructura sanitaria ${ }^{34}$, y del carácter relacional entre el deber de protección, a cargo de la administración pública, frente al interés del ciudadano

33 CAstronovo, Carlo. «La relazione come categoría essenziale ...». Ob. cit., p. 61, y «La relación como categoría esencial...». Ob. cit.,, p. 53.

34 CASTRONOVO, Carlo. «La relazione come categoría essenziale ...». Ob. cit., pp. 63-64, y «La relación como categoría esencial...». Ob. cit., p. 55. 
de obtener un procedimiento legítimo en vista de un pronunciamiento Ilegítimo ${ }^{35}$.

La relación obligatoria normalmente se construye mediante una estructura binaria entre derecho de crédito y deber de prestación. Dicho deber nace como consecuencia eventual de una fuente específica, en particular el contrato, los deberes y situaciones pertenecientes a la relación marco encuentran su fundamento en la ley, bajo el presupuesto de una relación que se ha instaurado entre las partes. La diferencia entre estos dos aspectos de la relación se encuentra no solo en el contenido sino en el orden de prioridad, el cual se refleja en las fuentes respectivas. Mientras que la relación marco nace directamente de la ley, como reflejo de la cualificación del contacto social según el criterio de la buena fe, la prestación nace necesariamente en el marco instaurado de esta manera, pero no automáticamente, sino por la elección específica que se traduce en un contenido siempre diferente, porque es función de una precisa voluntad de las partes o de un fin determinado. Y mientras que la relación marco es la relevancia jurídica de la relación instaurada en el plano fáctico, el deber de prestación es el efecto específico querido (por las partes o por la ley), que se inserta en dicha relación ${ }^{36}$.

LOS CONTRATOS

CON DEBERES DE

PROTECCIÓN:

A PROPÓSITO DE

LA VINCULACIÓN

ENTRE EL

DERECHO

CONSTITUCIONAL

Y EL DERECHO

CIVIL

CONTRACTS WITH

PROTECTION

DUTIES. A

PROPOS OF

CONSTITUTIONAL

AND CIVIL LAW

CONNECTION

\section{CLÁUSULA GENERAL DE BUENA FE}

El contexto normativo italiano de la buena fe es diferente del peruano. En el Código Civil italiano de 1942 se discutió sobre dos conceptos: (i) la lealtad regulada en el artículo 1175 [El deudor y el acreedor deben comportarse con arreglo a las reglas de la lealtad — correttezza-], y (ii) la buena fe normada en el artículo 1375 [El contrato debe ser ejecutado con arreglo a la buena fe]:

[...] o se trata de conceptos que, aplicándose a las mismas situaciones, son fundamentalmente conceptos diversos, o se trata de conceptos que, idénticos en el plano del contenido y aplicables a las mismas situaciones, se refieren a momentos diversos de ellas (como acaecería si se quiere referir la lealtad a la integración, la buena fe a la ejecución), o se trata de un único concepto, expresado en variantes lexicales, pero aplicado a situaciones, momentos, niveles idénticos ${ }^{37}$.

Para otra doctrina, ambas normas señalan una única regla de comportamiento ${ }^{38}$.

35 CAstronovo, Carlo. «La relazione come categoría essenziale ...». Ob. cit., pp. 65-66, y «La relación como categoría esencial...». Ob. cit., pp. 55-56.

36 CAStRonovo, Carlo. «La relazione come categoría essenziale ...». Ob. cit., pp. 68-69, y «La relación como categoría esencial...». Ob. cit., pp. 58-59.

37 RODOtÀ, Stefano. Le fonti di integrazione del contratto. Ob. cit., p. 143.

38 FERRI, Giovanni Battista. Ordine pubblico, buon costume e la teoria del contratto. Milán: Giuffrè, 1970, p. 119, y BIANCA, Massimo. Dell'inadempimento delle obbligazioni, Art. 1218-1229. Segunda edición. 
En todo caso, se puede aseverar que los «civilistas italianos han promovido exitosamente su reconocimiento, con carácter general, sobre la base del artículo 1175 del Código de 1942, que obliga a los sujetos de la relación obligatoria a comportarse con arreglo a la lealtad (correttezza)» ${ }^{39}$.

La buena fe y la lealtad son reguladas conjuntamente en el Draft Common Frame of Reference (DCFR) mediante las expresiones good faith y fair dealing en los artículos I.- 1:102 [inciso b del numeral 3]; II.- 1:102 [numeral 1]; II.- 3:301; II.- 7:201 [II del inciso b del numeral 1]; II.- 7:205 [numerales 1 y 3]; II.- 7:207 [numeral 2]; II.- 7:215 [numeral 2]; II.- 8:102 [inciso g del numeral 1]; II.- 9:101 [inciso c del numeral 2]; II.- 9:404; II.- 9:405; II.- 9:406; III.- 1:103; III.- 1:106 [numeral 4]; III.- 3:105; III.-3:203 [inciso b]; IV. b.- 4:102 [numeral 2], y vi.- 5:401 [inciso b del numeral 2].

$\mathrm{El}$ «contenido de la lealtad debe ser determinado con un reenvío a un orden de consideración legislativamente determinado, y concretamente individualizado en las normas constitucionales» y por ello su función es ser «límite de la autonomía privada» ${ }^{40}$.

El parámetro para definir el contenido de la lealtad considera «en primer lugar, los principios constitucionales en la materia de los derechos y de los deberes de los sujetos privados; en segundo lugar, de los lineamientos generales que el principio de la solidaridad ha asumido en el sistema civilístico (también, debe recordarse, por efecto de los nominados principios constitucionales) $»^{41}$. De ahí que el criterio de lealtad se especifica en dos direcciones: «como criterio idóneo para permitir la formación de una norma contractual que haga posible la realización completa de la operación económica perseguida por las partes», y «como criterio que, compatiblemente con el tipo de reglamento de intereses perseguido por las partes, permite la formación de una norma contractual adecuada a las finalidades del orden social perseguidas por el ordenamiento» ${ }^{42}$.

La buena fe como cláusula general está definida - por el legislador del Código Civil italiano de 1942 - por «los principios de lealtad y honestidad en toda la mutación contractual, de la fase de formación, eventualmente caracterizada por el desarrollo de las tratativas, hasta la ejecución $»^{43}$. En concreto, la ley es la fuente inmediata y mediata de los deberes de protección a través de la cláusula general de la buena $\mathrm{fe}^{44}$.

Boloña: Zanichelli, 1979, pp. 76-77.

39 LEÓN, Leysser. Ob. cit., pp. 37-38.

40 RODOTÀ, Stefano. Le fonti di integrazione del contratto. Ob. cit., p. 181.

41 lbíd., p. 151.

42 lbíd., p. 152.

43 PATTI, Salvatore. «L'interpretazione delle clausole generali». Rivista di diritto civile, LIX, 2 (2013), pp. 263-296, p. 275. Padua: Cedam.

44 CAstronovo, Carlo. «Obblighi di protezione». Ob. cit., p. 4. 
En el Perú, se puede sostener que los deberes de protección nacen de la cláusula general de la buena $\mathrm{fe}^{45}$.

El artículo 1362 del Código Civil regula la cláusula general de la buena fe:

Las cláusulas generales están contenidas en normas jurídicas. Interpretar las cláusulas generales significa, por eso, interpretar las normas jurídicas que la prevén. Por lo tanto, se trata de interpretar la ley, es decir, de atribuir a la norma un significado que permita la subsunción del caso concreto, pero las reglas establecidas para la interpretación de la ley se demuestran insuficientes o no adaptadas para atribuir el referido significado a las normas que contienen cláusulas generales ${ }^{46}$.

La interpretación de la cláusula general

consiste en el hecho de que no se trata tanto de subsumir un determinado comportamiento bajo una norma que prevé un modelo abstracto, sino de individualizar, a la luz de directivas formuladas por la norma y de las circunstancias del caso, cómo el comportamiento deba considerarse correcto ${ }^{47}$. «El juez llamado a resolver el caso hace referencia a la norma que prevé la cláusula general, pero en realidad aplica la regla que gobierna el grupo de casos en los que se subsumen a su examen, sin perjuicio de la posibilidad de usar la cláusula general para adaptar la regla concreta a las exigencias del nuevo caso o para elaborar una nueva» ${ }^{48}$.

La reconstrucción del contenido de las cláusulas generales se hace mediante las «normas constitucionales» ${ }^{49}$. Dicho contenido es «flexible» porque «permite adaptar la regla a las peculiaridades del caso concreto» mediante «la función de permitir al juez de adaptar las normas a las circunstancias del caso concreto y de colmar las inevitables lagunas de reglamentación» ${ }^{50}$. Con relación a la buena fe, la vía correcta de establecer el contenido de las reglas de la buena fe es «extraer una multiplicidad de parámetros de juicio, suficientemente específicos, respecto de la diversidad de los sectores de uso de la buena fe y la variedad de los conflictos de intereses, pero suficientemente elaborados para ser fungibles a una pluralidad de situaciones y controlables y predecibles en su uso», y tal tarea está reservada a la jurisprudencia «en el cotidiano contacto con la realidad de las relaciones jurídicas y a sus capacidades de realizar el equilibrio dialéctico entre normas y casos» ${ }^{51}$.

45 ZAMUdIO EsPINAL, Carlos. «Responsabilidad por incumplimiento de deberes de protección». Revista Jurídica del Perú, 77 (2007), pp. 195-205, p. 202. Lima: Gaceta Jurídica.

46 PATTI, Salvatore. Ob. cit., pp. 265-266.

47 Ibíd., p. 278.

48 Ibíd., p. 290.

49 RODOTÀ, Stefano. Le fonti di integrazione del contratto. Ob. cit., p. 191.

50 PATTI, Salvatore. Ob. cit., p. 287.

51 BESSONE, Mario y Andrea D’ANGELo. «Buona fede». En Enciclopedia giuridica. Volume V. Roma: Istituto de la Enciclopedia Italiana, Istituto Poligrafico e Zecca dello Stato, 1988, pp. 1-8, p. 7.

LOS CONTRATOS

CON DEBERES DE

PROTECCIÓN:

A PROPÓSITO DE

LA VINCULACIÓN

ENTRE EL

DERECHO

CONSTITUCIONAL

Y EL DERECHO

CIVIL

CONTRACTS WITH

PROTECTION

DUTIES. A

PROPOS OF

CONSTITUTIONAL

AND CIVIL LAW

CONNECTION 
En Italia se ha señalado que el artículo 1175 del Código Civil italiano de 1942 «trasciende el ámbito de las relaciones contractuales; pero, valorada con relación al contrato, no hay duda de que se aplica como fuente de integración del reglamento negocial $»^{52}$. El concepto de lealtad es una variante del principio de buena fe y

[...] asume el rol de fuente de integración del contrato para salvaguardar el interés de protección de cualquier parte, y también de los terceros ligados a una de ellas de particulares relaciones que se asocian al mismo riesgo específico. En primer lugar, se deduce que la lesión de tal interés producto de comportamientos de la contraparte causalmente vinculados a la ejecución del contrato cambia naturalmente: no se concreta en un ilícito civil, como sucedería fuera del ámbito del artículo 1175, sino en un acto de incumplimiento del contrato sujeto a la regla del artículo 1218 [Responsabilidad del deudor.- El deudor que no realiza exactamente la prestación debida está obligado al resarcimiento del daño, a menos que pruebe que el incumplimiento o el retardo han sido determinados por imposibilidad de la prestación derivada de causa no imputable a él]. En segundo lugar, un comportamiento contrario a un deber [obbligo] de protección puede asumir relevancia jurídica independientemente de la producción del daño actual, en función de los remedios de la resolución del contrato y de la excepción de incumplimiento ${ }^{53}$.

Ahora bien, es importante señalar que el deber contractual de buena fe es una derivación del deber legal de buena fe regulado en el artículo 1362 del Código Civil peruano. La buena fe en la norma citada es un deber legal. «El acto debido según la buena fe asume su carácter de obligatoriedad en virtud de un fenómeno de integración contractual y se aplica mediante la cláusula general de buena fe, la cual tiene un fundamento normativo de tipo legislativo [...] Teniendo en cuenta el aspecto genético del deber de buena fe, debería, en consecuencia, ser calificado como deber legal, hallando su propia fuente, precisamente, en la ley» ${ }^{54}$.

Entonces, no hay duda de que la buena fe es un deber legal, pero cuando se celebra un contrato, nace un deber contractual de buena fe con un valor jurídico único y concreto aplicable al contrato en particular. De esta manera, «el deber es contractual en cuanto efecto jurídico producido por un acto contractual concreto individualizado en sus características estructurales creado por una manifestación de voluntad de los contratantes» ${ }^{55}$. Este concepto de deber contractual de buena fe requiere otro concepto para su mejor entendimiento: el reglamento contractual como «conjunto de cláusulas contractuales y 
de las consecuencias jurídicas que originan, en una óptica subjetiva, las posiciones jurídicas activas y pasivas y justifican la mutación económico-contractual» ${ }^{56}$. De ahí que el deber contractual de buena fe es una derivación del reglamento contractual y cumple un rol fundamental tanto en el cumplimiento como en el incumplimiento de las obligaciones:

Verificada la presencia del deber de buena fe en el reglamento de los intereses deducidos del contrato, en el sentido que la buena fe (como fuente de integración) participa en la determinación de los actos debidos de modo que el contrato logre la realización del programa económico; verificada también la «necesidad», bajo el nivel funcional, que el deber de buena fe se aplica en la ejecución de modo que el contrato pueda funcionar $[\ldots]$, resulta evidente la influencia «fisiológica» del deber de buena fe.

Dado que la función desarrollada por el deber de buena fe de salvaguardar el contrato en su aspecto dinámico, permitiendo la realización del programa económico y así de los intereses de las partes contratantes, parece evidente que su incumplimiento influye sobre la total mutación contractual, en el sentido que impide regular el funcionamiento del contrato y la obtención del resultado económico.

La cualidad del deber de buena fe como deber contractual se aplica, por eso, también en la eventual mutación patológica del contrato. El hecho mismo de que la falta de ejecución del deber de buena fe comporte una anomalía funcional del contrato expresa su naturaleza de deber contractual por cuanto el acto debido, por su instrumentalidad a la obligación principal, se realiza para lograr la utilidad económica contractual, si no se ejecuta impide también su exacta ejecución y por ello el incumplimiento del contrato.

Esto demuestra, en esencia, que la obligatoriedad jurídica del acto de buena fe no deriva de una general, y neutral bajo el aspecto teleológico, exigencia de comportamiento correcto de los contratantes, sino viceversa de la específica exigencia económica relevante en el ámbito del particular acto contractual, y por ello funcionalmente dirigido al resultado económico-contractual.

Incluso en el aspecto teleológico, por ello, la exigencia que es el fundamento y justifica el deber de buena fe es una exigencia específica, individualizada en la particular relación económica deducida del contrato.

En conclusión, el deber de buena fe debe ser calificado como un verdadero y propio deber contractual en virtud de una serie de valoraciones: no solo en base a su idoneidad de colocarse como 
acto jurídicamente debido en el ámbito de una particular mutación contractual, sino también en consideración al hecho de que tal acto debido está teleológicamente ligado a la exigencia económica propia de la relación contractual y también está funcionalmente coligada a la realización del interés económico contractualmente deducido, de modo que su eventual incumplimiento impide la satisfacción, impidiendo además regular el funcionamiento del contrato ${ }^{57}$.

El «deber de buena fe está ligado por una relación funcional, en su mutación fisiológica, con la prestación contractual principal, y en consecuencia con el relativo interés - «externo» estructuralmente a la relación obligatoria de buena fe-, así su violación, en su aspecto patológico, se traduce en una anomalía funcional, en el sentido de la ruptura de la mutación dinámica del contrato, con la subsiguiente falta de realización del interés de la contraparte y, más en general, del programa económico convencionalmente establecido. Propiamente, la subsistencia de la anomalía funcional, dado el requisito de la gravedad, justifica, sobre el plano lógico y sobre el plano aplicativo, el recurso al remedio de la resolución del contrato» ${ }^{58}$. Entonces, la violación del deber contractual de buena fe otorga los derechos de resolución, de resarcimiento y de cumplimiento, entre otros remedios.

Ahora bien, el deber de buena fe está indudablemente coligado a las obligaciones principales y secundarias de un contrato, pero ello no comporta que este deber no mantenga su autonomía. Nos explicamos mejor. En el caso hipotético de que el deudor incumpla una obligación principal, el acreedor puede optar por ejercer el derecho de resolución, y en su caso, ejercer el derecho de resarcimiento (artículo 1428 del Código Civil) si dicho incumplimiento le ocasionó daños. Pero si el incumplimiento se refiere al deber de buena fe, el acreedor podría ejercer ambos derechos aunque la obligación principal no haya sido incumplida. Incluso si el deudor incumple una obligación principal, el acreedor podría optar por una terminación unilateral o desistimiento utilizando la denominada «resolución» por intimación o por autoridad del acreedor regulada en el artículo 1429 del Código Civil, sin perjuicio de que posteriormente ejerza su derecho de resarcimiento si además el deudor incumplió algún deber emanado de la reglas o deberes de buena fe. De ahí que se puede sostener que es perfectamente posible formular pretensiones de resolución y de resarcimiento que se sustenten en violaciones diferentes, y que no cabe contradicción entre pedir resolución por incumplimiento de una obligación principal y pedir el resarcimiento por incumplimiento de un deber de buena fe. 


\section{EJEMPLOS DE CONSTITUCIONALIZACIÓN DEL DERECHO CIVIL: LOS CONTRATOS CON DEBERES DE PROTECCIÓN}

Es usual en la actual praxis contractual minera estipular cláusulas sobre deberes de protección. Así, una empresa - comitente- dedicada a actividades mineras de exploración, explotación y beneficio de minerales, requiere los servicios de construcción, avance, desarrollo y sostenimiento, y otros trabajos de labores mineras que integran su unidad de producción. Por su parte, la contratista debe ser una empresa especializada en la ejecución de obras civiles y de labores mineras. La contratista asume el deber de proporcionar a su personal (trabajadores, supervisores y demás a su cargo) los implementos y equipos de seguridad necesarios para la debida protección de su seguridad y salud. La contratista asume el deber de efectuar las labores contratadas velando por los intereses económicos de la comitente y respetando la propiedad de terceros, así como los usos y costumbres de las poblaciones locales. La contratista está obligada a tomar las medidas técnicas de seguridad necesarias, lo que implica que deberá implementar las medidas de seguridad máximas para evitar la pérdida de los equipos, partes, piezas, repuestos, y cualquier otro bien de su propiedad por sustracción (robo) por terceros, y todas las medidas de seguridad requeridas para tal fin. Además, la contratista se obliga a cumplir cabalmente con las normas de medio ambiente, por lo cual será la única y directa responsable de la contaminación al medio ambiente y recursos naturales, dentro y fuera de la unidad de producción del comitente durante la ejecución de las obras, y la contratista se obliga frente al comitente a asumir total responsabilidad por los daños que esta o su personal pudieran ocasionar a las instalaciones del comitente, así como cualquier accidente que pudiera suceder al personal de la contratista, o que pudieren causar estos a terceros y a trabajadores del comitente, o que pudieran ocasionar al medio ambiente en las instalaciones del comitente.

Estas cláusulas mencionadas entre el comitente y el contratista se refieren a los deberes de protección que son asumidos exclusivamente por la contratista.

Por otro lado, hay algunos ejemplos legislativos y jurisprudenciales donde se aplican y se han aplicado los deberes de protección.

Un caso legislativo es el regulado en el segundo párrafo del artículo 1328 del Código Civil [también es nulo cualquier pacto de exoneración o de limitación de responsabilidad para los casos en que el deudor o dichos terceros violen obligaciones derivadas de normas de orden público], que tiene como antecedente el segundo párrafo del artículo 1229 del Código Civil italiano [es igualmente nulo todo pacto previo de exoneración o de limitación de responsabilidad por los casos en que

LOS CONTRATOS CON DEBERES DE PROTECCIÓN: A PROPÓSITO DE LA VINCULACIÓN ENTRE EL

DERECHO

CONSTITUCIONAL

Y EL DERECHO

CIVIL

CONTRACTS WITH PROTECTION

DUTIES. A

PROPOS OF CONSTITUTIONAL AND CIVIL LAW CONNECTION 
el hecho del deudor o de sus auxiliares constituya infracción de deberes de normas de orden público].

El segundo párrafo del artículo 1229 del Código Civil italiano se justifica porque, así como el deudor es responsable de los medios materiales empleados para el cumplimiento, él también debe ser responsable de las personas que utiliza en su empresa y que son extrañas a la relación para la cual ellas colaboran. De estas premisas se deduce un corolario lógico: puesto que los auxiliares no son, frente al acreedor, los directos responsables del incumplimiento, el pacto de no responsabilidad del deudor por los daños producidos por aquellos con dolo o culpa grave significaría una total insatisfacción para el acreedor ${ }^{59}$.

Sobre el pacto relativo a las prestaciones que interesan al orden público, también regulado en el segundo párrafo del artículo 1229 del Código Civil italiano, una doctrina italiana ha definido el orden público como el sistema de los principios fundamentales del ordenamiento que impone al deudor el deber inderogable de actuar diligentemente en la satisfacción de los intereses de protección del acreedor en su integridad física y moral, y en sus relaciones familiares ${ }^{60}$. Otra doctrina ha opinado que el orden público se refiere al conjunto de normas que tutela intereses generales ${ }^{61}$. Otra doctrina asevera que las normas de orden público se refieren a las normas que establecen la indisponibilidad de ciertos derechos o prevén zonas de tutela de los intereses del contratante más débil o del consumidor ${ }^{62}$.

En cuanto a las normas de orden público mencionadas en el segundo párrafo del artículo 1328 del Código Civil, debemos aseverar que las cláusulas de limitación o de exoneración de responsabilidad no deben violar normas constitucionales. Por ejemplo, normas de protección al medio ambiente, al derecho de los consumidores y al derecho de las personas (por ejemplo, el derecho a la integridad física). Es común en la contratación privada entre empresas estipular cláusulas donde las limitaciones o exoneraciones de responsabilidad previstas no serán aplicables en los casos señalados a continuación:

(i) Dolo, fraude o culpa grave.

(ii) Daños ambientales o violación de la legislación ambiental.

(iii) Daños referentes a la violación de propiedad intelectual de terceros.

59 BENATTI, Francesco. «Las cláusulas de exoneración de responsabilidad». En Leysser L. León. Derecho de las relaciones obligatorias, lecturas seleccionadas y traducidas para uso de los estudiantes universitarios. Lima: Jurista Editores, 2007, pp. 429-433, p. 431.

60 BIANCA, Massimo. Ob. cit., p. 482.

61 BENATTI, Francesco. «Las cláusulas de exoneración de responsabilidad». Ob. cit., p. 431.

62 CannatA, Carlo Augusto. L'inadempimento delle obbligazioni. Padua: Cedam, 2008, p. 74. 
(iv) Demandas causadas por el incumplimiento de pago de los tributos relacionados con la ejecución del contrato, o por violación a la legislación tributaria, laboral o administrativa.

(v) Demandas relativas a daños personales, incluyendo daños morales.

(vi) Daños causados por violación a la legislación penal o administrativa.

(vii) Daño que se derive de cualquier eventual demanda o reclamación de terceros que sea interpuesta en relación con lesiones corporales, enfermedad o muerte de cualquier persona, empleada o no, incluyendo visitantes, clientes, autoridades y prestadores de servicios en general.

Estas reglas de orden público no pueden ser limitadas o exoneradas contractualmente en cuanto a la responsabilidad, porque en el fondo no cabe limitar o exonerar el incumplimiento de deberes de protección al medio ambiente, al derecho de propiedad intelectual de terceros, a los intereses públicos y a los derechos de las personas en general.

Un caso jurisprudencial importante se desarrolló en la casación 3101 2009-Lima del 16 de marzo de 2010. Un grupo de bonistas [titulares de bonos] demandó por responsabilidad contractual al Banco Santander Central Hispano, sustituido por el Banco de Crédito del Perú, en su calidad de fideicomisario (representante de los obligacionistas) por actos consistentes fundamentalmente en no otorgar garantías reales a favor de los bonistas, no proteger adecuadamente el crédito de los bonistas y no impedir la constitución de garantías reales en favor de otros acreedores. Esta imputabilidad de negligencia atribuida al banco demandado como fideicomisario se debió a que nunca asistió a un Directorio ni a una Junta General de Accionistas de BASA, sino tan solo luego de habérselo exigido la Asamblea de Obligacionistas. Asimismo, el fideicomisario no revisó los libros ni la contabilidad de dicha empresa, ni solicitó ningún tipo de información a BASA. Tampoco solicitó a BASA la documentación necesaria para establecer la real situación financiera de la empresa, y no convocó a una Junta de Obligacionistas para informarles sobre la crítica situación económica financiera por la que atravesaba BASA. En virtud de ello, tampoco el banco demandado exigió el otorgamiento de garantías reales para respaldar la redención de los bonos y el pago de los intereses correspondientes.

El tercer párrafo del artículo 240 de la Ley General de Sociedades - ley 16123 y su modificatoria aprobada por decreto legislativo 311 y aplicable a la situación concreta - es claro al establecer que el fideicomisario tiene representación legal de los bonistas y puede ejercer las acciones que correspondan para cautelar los derechos de dichas personas. Más aún, 
en la primera asamblea de bonistas de BASA S.A., la asamblea de bonistas acordó por unanimidad «solicitar a BASA el otorgamiento de primera y preferente hipoteca sobre la planta industrial de su propiedad, por un monto de US\$ 4000000 más el 30\% de dicha suma, para coberturar la posible reducción del precio de venta del inmueble, según manifestó Profuturo AFP, más de un año de intereses».

Además, hubo conflicto de intereses entre el banco demandado como acreedor de BASA y como fideicomisario de los bonistas, en el sentido de que favoreció su situación patrimonial en detrimento de los bonistas. Este conflicto de intereses se demuestra al no haber protegido adecuadamente el crédito de los bonistas y al no haber impedido judicial o extrajudicialmente la constitución de garantías reales en favor de otros acreedores. Por tanto, el banco demandado privilegió su calidad de acreedor de BASA en contraposición a su calidad de fideicomisario de los bonistas. El embargo trabado a su favor por US\$5000 000 fue una prueba de ello.

La casación bajo análisis hizo suyos los argumentos de la sentencia de vista emitida por la Primera Sala Civil de la Corte Superior de Justicia de Lima del 20 de abril de 2009 (expediente 1508-2007). En el Fundamento Décimo Sétimo de esta resolución se menciona que las obligaciones del banco demandado deben encontrarse en una interpretación de lo pactado en el contrato de fideicomiso «a la luz del principio de la buena fe contractual previsto en el artículo 1362 del Código Civil». No hay duda que la imputación de responsabilidad al banco demandado fue por incumplir deberes de protección en su calidad de fideicomisario.

Otros casos sobre deberes de protección se desarrollaron en la jurisprudencia administrativa. En la resolución 1391-2007-CPC del 18 de julio de 2007 se señaló que «un consumidor razonable que acude a jugar a un casino y que entrega las llaves de su vehículo al servicio de valet parking ofrecido esperaría que, además de estacionamiento vehicular, se brinde servicio de vigilancia». En doctrina nacional se ha dicho con acierto que «la normativa del contrato de hospedaje se aplicará a los estacionamientos de los establecimientos comerciales porque, al igual que en el hospedaje, en dichos establecimientos el estacionamiento es una prestación accesoria. De esta manera, cuando los clientes estacionan sus vehículos, el deber de custodia es un deber de protección o de seguridad ${ }^{63}$. Por ello, era innecesaria la ley que regula el servicio de estacionamiento vehicular, ley 29461, porque «nuestro Código Civil

63 GutiéRREZ VegA, Nelly Renee. Responsabilidad civil del propietario o administrador de los estacionamientos de los establecimientos comerciales: un caso de aplicación de la teoría de los deberes de protección. Tesis para optar el título profesional de abogada. Pontificia Universidad Católica del Perú, 2010, p. 247. 
tiene las herramientas para resolver los casos de pérdidas de los vehículos en los estacionamientos de los establecimientos comerciales» ${ }^{64}$.

Por otro lado, el fundamento 32 de la sentencia del Tribunal Constitucional del 11 de noviembre de 2003 (expediente 0008-2003-AI/ TC, Lima) ha establecido que «los derechos de acceso al mercado, a la protección de los intereses económicos, a la reparación por daños y perjuicios y a la defensa corporativa del consumidor, se erigen también en derechos fundamentales reconocidos a los consumidores y usuarios». Así, se puede colegir que si hay deberes de protección existen correlativamente derechos de protección para los consumidores en el marco de un contrato de consumo.

No obstante ello, en sede nacional se han dicho dos cosas contradictorias. Por un lado, se ha dicho que «los deberes de protección se constituyen en autónomos respecto de los que les corresponden al Estado respecto de los consumidores, siendo enteramente privados, obligan a su cumplimiento, en la medida que ignorarlos puede derivar en responsabilidad por incumplimiento de deberes de protección derivados del deber principal de cooperación ${ }^{65}$ y en la conclusión décimo cuarta de la tesis que «hay coincidencia de fines entre estos deberes [de protección], puesto que aquellos que competen al Estado se despliegan en el marco de las relaciones jurídicas intersubjetivas y terminan siendo similares a los deberes de protección obligacionales» ${ }^{66}$. Los deberes de protección del Estado son totalmente diferentes de los deberes de protección que deben ser cumplidos por los proveedores o empresarios en el marco de un contrato de consumo. El Estado y los proveedores o empresarios cumplen roles diferentes.

Finalmente, la resolución del 24 de mayo de 2000, emitida por la Tercera Sala Civil de Lima (expediente 1615-2000), hace mención a la obligación tácita de seguridad la cual no se agota en el acto material de la transfusión, sino que la obligación va más allá, porque no solo se obligan a realizar la transfusión sino también a que dicha transfusión no sea causa de un mal para el paciente.

No hay duda que esta posición considera convenientemente que la actividad de transfusión implica el cumplimiento de deberes de conservación de la esfera jurídica de otros que nacen de la confianza inevitablemente generada por la misma profesionalidad. La violación de tales deberes conllevará a la responsabilidad contractual nacida de

64 lbíd., p. 250.

65 HowaRd DEJo, Paul Iván. Los deberes de protección a favor del deudor-consumidor: ¿exceso de protección del Estado o la obligación como medio efectivo de cooperación intersubjetiva? Tesis para optar el grado de Magíster en Derecho Civil. Lima: Escuela de Posgrado de la Pontificia Universidad Católica del Perú, 2010, p. 164. 66 Ibíd.

LOS CONTRATOS

CON DEBERES DE

PROTECCIÓN:

A PROPÓSITO DE

LA VINCULACIÓN

ENTRE EL

DERECHO

CONSTITUCIONAL

Y EL DERECHO

CIVIL

CONTRACTS WITH

PROTECTION

DUTIES. A

PROPOS OF

CONSTITUTIONAL

AND CIVIL LAW

CONNECTION 
un deber sin prestación o deber de protección o de deber de seguridad inherente a la conducta (Verkehrspflichten) ${ }^{67}$.

\section{PALABRAS FINALES}

\section{La teoría de los deberes de protección}

[...] no tiene la función política de corregir o compensar deficiencias de la regulación del ilícito civil, y por eso no se vincula con los desarrollos de tal regulación. Ella tiene un preciso fundamento dogmático en las normas que configuran la relación obligatoria como una relación compleja cuyo propósito de tutela comprende, más allá del interés de la prestación definido por el artículo 1174 [Carácter patrimonial de la prestación. - La prestación que constituye el objeto de la obligación debe ser susceptible de valoración económica y debe corresponder a un interés, aun cuando no sea patrimonial, del acreedor], el interés de protección en consideración a una norma sucesiva. Del mismo modo, el artículo 1175, y en la medida en que estén involucrados, los deberes [obblighi] de protección reciben su determinación de sentido no en el deber genérico de neminem laedere, sino en la relación específica que forman parte. La relación obligatoria, entendida como relación fundamental, no es una entidad normativa ontológicamente diferente de las particulares obligaciones [obblighi] y derechos que forman parte, sino ni siquiera es simplemente una suma. Ella posee su autonomía en cuanto los elementos particulares son esencialmente determinados por su posición en la estructura unitaria de la relación; si fueran separados cesarían de ser aquello que era antes. El efecto práctico de esta teorización, llevada a cabo sobre la base de la teoría general de las estructuras complejas, es la calificación de los comportamientos contrarios a los deberes [obblighi] de protección como violaciones contractuales positivas, es decir, incumplimientos contractuales, ella es alternativa, no concurrente con la calificación como actos ilícitos ${ }^{68}$.

La categoría de los deberes de protección se fundamenta adicionalmente en la defensa de la persona humana y el respeto de su dignidad, los cuales «constituyen el fin supremo de la sociedad y del Estado» ${ }^{69}$. Ello debe realizarse mediante una adecuada interpretación constitucional: «interpretar la regla legal existente conforme a los principios constitucionales, adoptando, entre otros sentidos posibles, aquel que

67 Morales Hervias, Rómulo. «Responsabilidad civil de las estructuras sanitarias y del Ministerio de Salud por transfusión de sangre infectada». Diálogo con la jurisprudencia, 12, 109 (octubre 2007), pp. 21-27, p. 27. Lima: Gaceta Jurídica.

68 MENGONI, Luigi. Ob. cit., p. 288.

69 LANDA, César. «La fuerza normativa constitucional de los derechos fundamentales». En Víctor BAZÁN y Claudio NASH (eds.). Justicia constitucional y derechos fundamentales. Fuerza normativa de la Constitución. Montevideo: Fundación Konrad Adenauer, 2011, pp. 17-42, p. 37. 
mejor se compatibilice con el ordenamiento constitucional ${ }^{70}$. En este sentido, el principio de protección a la dignidad y la cláusula general de la buena fe deben ser leídos en dos planos distintos: «los principios pertenecen noalajustificación "interna" delas decisiones jurisdiccionales, sino a su justificación "externa", o sea a la argumentación que justifica la elección de las premisas — en particular de la premisa normativa- de la justificación interna. La aplicación de un principio exige, por lo tanto, concretización, puesto que "aplicar" un principio consiste precisamente en concretarlo» ${ }^{71}$.

Así las cosas, los deberes de protección no solo forman parte de los deberes legales emanados de la cláusula general de la buena fe, sino del deber de protección de la dignidad de los sujetos del principio que emana de la norma constitucional. Tampoco debe prescindirse de saber que las cláusulas generales funcionan al interior de los principios ${ }^{72}$. Aquí sostenemos que la cláusula general de la buena fe funciona adecuadamente bajo el principio de la protección de la dignidad de los sujetos.

LA VINCULACIÓN

\section{ENTRE EL}

DERECHO

CONSTITUCIONAL

Y EL DERECHO

CIVIL

CONTRACTS WITH

PROTECTION

DUTIES. A

PROPOS OF

CONSTITUTIONAL

AND CIVIL LAW

70 ÁvILA, Humberto. “"Neoconstitucionalismo": entre la "ciencia del Derecho" y el "derecho de la ciencia"». Laura Criado Sánchez (trad.) y Renzo Cavani (rev.). Gaceta Constitucional, 66 (2013), pp. 203-217, p. 211. Lima: Gaceta Jurídica.

71 GUASTINI, Riccardo. «A propósito del neoconstitucionalismo». Renzo Cavani (trad.) y Vitor de Paula Ramos (rev.). Gaceta Constitucional, 67 (2013), pp. 231-240, p. 239. Lima: Gaceta Jurídica,

72 VeluzzI, Vitto. Le clausole generali. Semantica e politica del diritto. Milán: Giuffrè, 2010, p. 81. 